\title{
أثر التقنيات الحديثة في تناهي وتطوير حركة النشر الأكاديمي
}

أ.د. فاضل عبد الزهرة مز عل / كلية التربية / جامعة البصرة

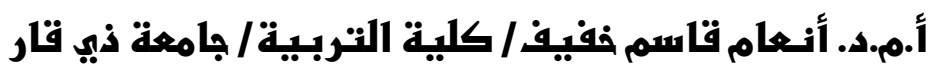

|لاقدميمة

يشهد العالم اليوم انفجاراً علميا هائلا وثورة نوعية كبرى في مجال المعلومـات، وأصبح من خـلال ذلك العـالم كله قريـة صغيرة فيمكن نقل أي خبر في مدة زمنيـة وجيزة وذلك عبر الأقمار الصناعية و الكمبيوتز و الإنترنت و التلفاز و غير ذلك.

ولما كان و اجب على الأكاديميين و اصحاب البحوث تبليغ هذه الافكار العلميـة للطلبة والمهتمين بهذا الهجال جميعاً كان من الضروري أن تستخدم كل وسيلة وتقنية حديثة تخدم هذه الدعوة بحيث يمكن توظيفها وحسن استغلالها لإبراز الصورة الناصعة للعلم و المعرفة الذي بنى أعظم حضـارة وفق علوم مرتبة ومنظمة ومن خلال هذه الإشارة لتبين إيجابيات وسلبيات استخدام هذه التقنيات الحديثة في النشر العلمي الاكاديمي وكذلك تحقيق مدى توظيف التقتيات الحديثة في خدمة هذه النشر العلمي من أجل الوصول إلى الطريق الأمثل لتوظيفه.

مفهوم النشر: للنشر تعاريف عديدة ومختلفة وردت في الكثير من أدبيات البحث العلمي، ومن بين

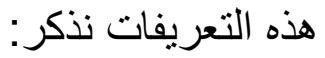
* النشر لغة: هو الإذاعة أو الإثاعة أو جعل الثيء معروفا بين الناس، والنشر اصطلاحا لا يبعد عن

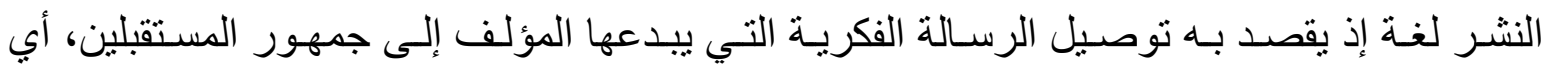
المستهلكين للرسالة]1].

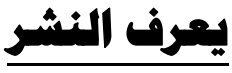

* على أنه مجموع العمليات الني يمر بها المطبوع من أول كونه مخطوطا حتى يصل يد القارئ.[2]. * هو العملية التي تتضمن جميع الأعمال الوسيطة بين كتابة النص الذب يقوم به المؤلف ووضع هذا النص بين أيدي القراء عن طريق المكتبات التجارية و الموز عين.

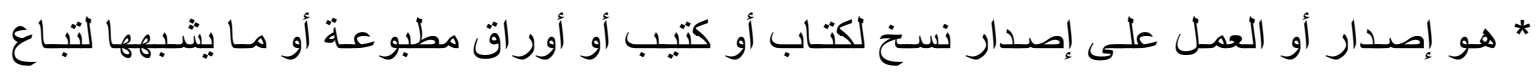

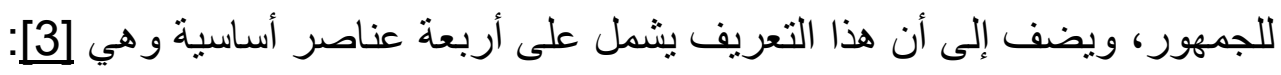
النشر الإكتروني: والمقصود بـه أنه مرحلة يستطيع فيها كاتب المقال أن يسجل مقاله على إحدى وسائل تجهيز الكلمات، ثم يقوم ببثه إلى محرر المجلة الإلكترونية، الذي يقوم بالتالي بجعله متاحا في

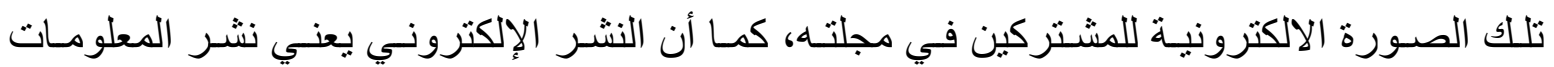


التقليديـة عبـر تقنيـات جديـدة تسـتخدم الحاسـبات وبـر امج النشـر الإكترونسي في طباعـة المعلومـات وتوزيعها ونشر هاب[4].

\section{هزايا النشر الالكتروني والنشر التقايدي}

إن التقنيات الحديثة تعمل على إحداث تحو لات جو هريـة في عمليـة نشر و توزيـع المعلومات لأن الهدف لأي نظام معلوماتي هو استغلال المعلومات و استثمار ها للرفع من مستويات التعليم ونشجيع المساهمة في اتخاذ القرار لتقدم البشرية و لعل أبرز مـا يقدمـه هو خدمة النشر الاككترونسي الذي أثر كثيراً على النشر الورقي لمـا حققه مـن مز ايـا لم تتو افر في الأخير[5]. .

\section{1}

في حالة النشر التقليدي: يكون المؤلف محظوظ لو وجد دار نشر أو مطبعـة تشـتري الكتاب منه أو تطبعه على حسابها مما يوفر عليه بعض التكاليف، و العادة أن اسـم المؤلف وعدد كتبه له تأثير على سـهولة النشـر، كمـا تشـرط بعض دور النشـر أن يكون الكتـاب مقرر در اسي، أو لله علاقة بمتطلابات السوق لكي تقبل أن تنشره على حسابها. أما لو كان سـيء الحظ ولم يجد دار نشـر تطبع كتابهه على حسـابها فسيضـطر أن بطبع كتابهه على حسـابه الخـاص و هـذا مكّلف، إذ أن أغلب دور النشـر أقل كميـة تطبعها مـن . . . 1 نسـة إلى . . . . نسخة علماً بأن هذه الكمية هي فقط التي استلمها المؤلف ، وهنالك كميـات أخرى هـ خلف الستار، تتصرف بها دور النشر وتبيعها[6] 16] 111$]$ أما في حالـة النشر الالكتروني: تتحمدل دور النشـر الالكترونيـة كل تكـاليف النشر بالإضـافة إلى تكاليف تحو يل الكتب الورقية الى كتب الكترونية وتكـاليف العرض و النقل ويحصل صـاحب المؤلّهف على نسب من مبيعـات كتابـه. كمـا يستطيع المؤلف نشـر عمله مباشـره على الموقع الخاص به بكل سـهولة ويسر وبدون الحاجـة للتعامل أصـلاً مـع دور النشـر. و نلاحظ في النشر الالكتروني انعدام وجود تكلفة الطباعة على الـورق والتجليد و التغليف

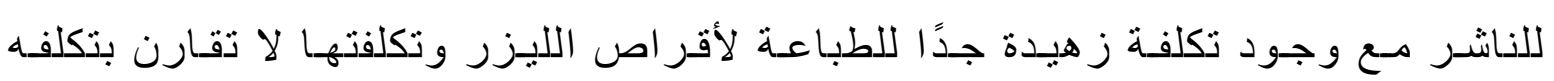

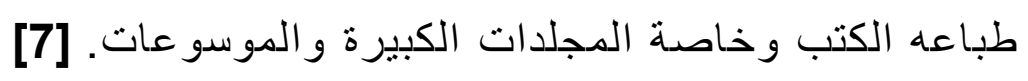

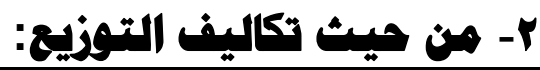

في حالـة النثـر التقليـدي سـيختار المؤلف إمـا أن يقوم بذوزيـع الكتـاب علىى ذفقته

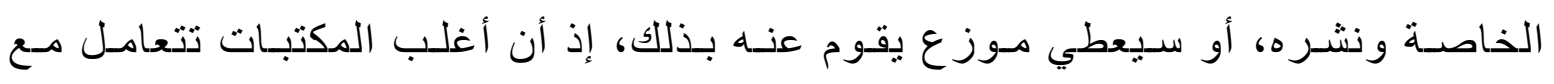
الموز عين وفي كلا الحالتين سيتكبد المؤلف بتكاليف إضدافية ربما لم تكن في حسبانه. أمـا 
في حالة النشر الالكتروني فيتم تسـويق وذوزيـع المحتوى الإلكترونسي من خلال البو ابـات و المو اقـع الالكترونيـة و محركـات البحـث و بهـذا تكـون العلاقـة مباشـرة بـين الناشـر و المستخدم النهائي فلا حاجة لوكلاء و لا موز عين. r- هن هيش تكاليف التخرنين و الشمثن:

إن تكلفة تخزين ونقل وشـدن الكتب الورقيـة ضـخمة مقارنـة بالنسـخ الإلكترونيـة سواء على أقر اص الليزر أو التي يتم تحميلها من خلال المواقع والبوابات الإلكترونية.

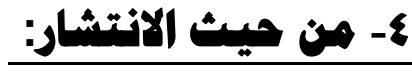

إتاحـة المحتـوى الإلكترونـي مـن خـلال الإنترنـت يعنسي السـرعة الفائقة في النشـر و إمكانيـة الحصدول عليهه في أي مكسان في العـالم متجـاوز كل الحدود الجغر افيـة ، وذلك بمجرد نشره على الموقع أو البوابة وبدون وجود أي حواجز مما يتيح فتح أسدواق كثيرة

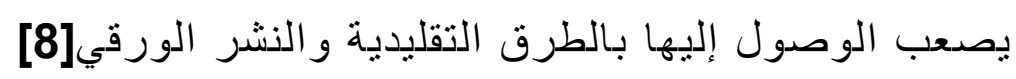

\section{0- من شيش الاستمشارية:}

فمن الوارد جدا أن يقع المؤلف الذي استخدم الطريقة التقليدية في النشر في فخ ذفاذ مطبو عاته في حين أن النشر الالكترونسي لا بمكن أن ينفذ فهو متاح دائمسا وفي أي وقت للتحميل و الاستفادة منه.

\section{7- هن هيث هقوق الاكية الفكرية:}

في الو اقع تعتبر هذه ميزة و نقطة إيجابيـة مهمهة يتمتع بهـا النشـر التقليدي و يسبق فيها نظيره الالكتروني و ذلك لسهولة نسخ المحتوى الإلكترونسي مقارنـة بالكتاب الورقي و عدم وجود ضدو ابط تحكم القرصنة على شبكه الأنترنت حيث يتم نشر المحتوي المسروق بدون الرجوع للمؤلف وقد يحدث فقد معلومات المؤلف من مصدر المعلومات الرقمسي، أو قد توضـع بغير أسـهه، كمـا أنه في بعض الأحيـان ربمـا تظهر بيانـات المؤلف صـحيحة وسليمة ولكن قد يحدث تغيير في محتويـات مصددر المعلومـات الرقمي وذلك بإضـافة أو حذف محتوياته بغير علم المؤلف ور غبته و التي ربما تؤدي إلى ظهور اسـم المؤلف على مادة أو أفكار تختلف مع معتقداته وقناعاته] وفي النهايـة لابـد أن يأخذ بعـين الاعتبـار كل النقاط السـابقة قبـل أن يقرر كيـ سينشـر محتو اه الكترونيا أم ورقيا و تقليديا. 


\section{الهواهش والمصادر :}

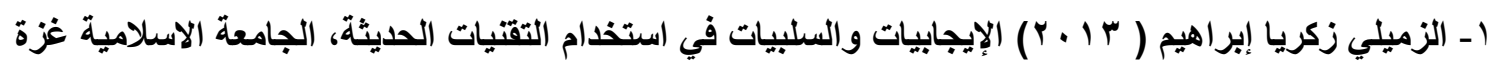

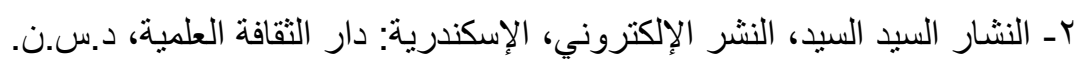

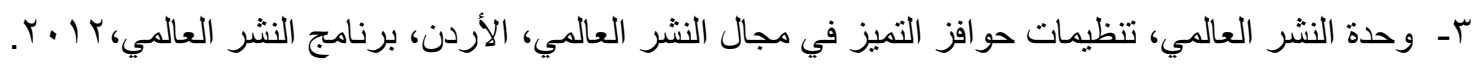

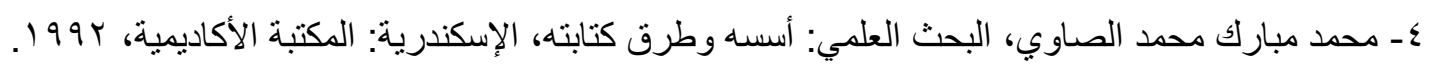

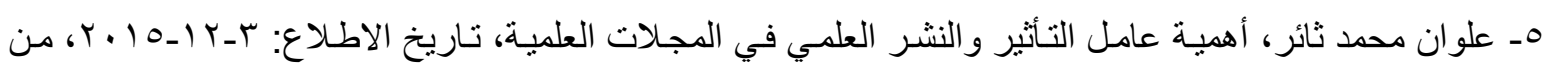

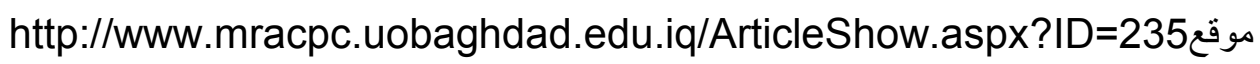
7- أمزيان برغل محمد، اتجاهات أساتذة علوم الإعلام والاتصـال في الجزائر نحو تقنتية النثر الالكتروني، (مذكرة

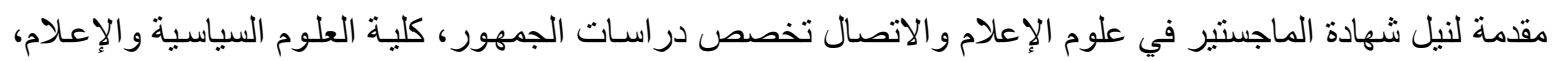

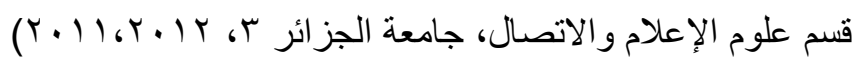

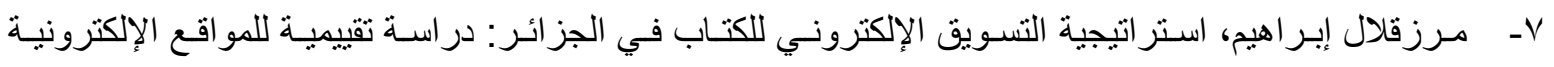

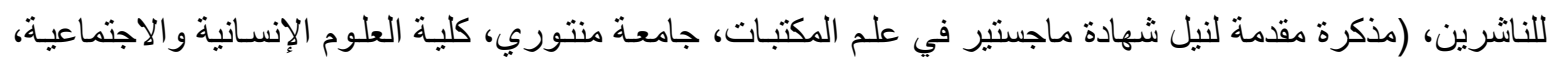

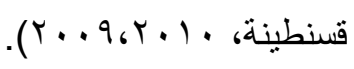
9- بن صـالح العقلا سليمان، تسويق الكتاب العربي: الصعوبات و التصور ات، ورقة بحثية مقدمة لصالح جامعة الملك

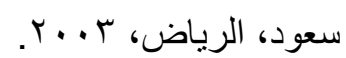
9- سعيد مقبل رضا، النشر الجامعي في العنصر الرقمي. ورقة بحثية قدمت في مؤتمر حركة نثر الكتب في مصر،

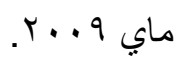

